\title{
DESENVOLVIMENTO COGNITIVO, AUDITIVO E LINGUÍSTICO EM CRIANÇAS EXPOSTAS À MÚSICA: PRODUÇÃO DE CONHECIMENTO NACIONAL E INTERNACIONAL
}

\section{Cognitive, auditory and linguistic development in children exposed to music: production of national and international knowledge}

\author{
Mayra Lopes Eugênio ${ }^{(1)}$, Júlia Escalda ${ }^{(2)}$, Stela Maris Aguiar Lemos ${ }^{(3)}$
}

\begin{abstract}
RESUMO
A música é um fator ambiental importante para o desenvolvimento das habilidades motoras, auditivas, linguísticas, cognitivas, visuais, entre outras. Estudos recentes citam a relação entre o estudo da música e o aprimoramento do processamento auditivo, das habilidades linguísticas e metalinguísticas e dos processos cognitivos, que são habilidades inerentes à comunicação humana. A Fonoaudiologia se ocupa da aquisição e do desenvolvimento, bem como, do aperfeiçoamento das habilidades necessárias à comunicação humana. Assim, parece haver uma inter-relação entre as áreas Música e Fonoaudiologia. O objetivo deste estudo é descrever e analisar as produções científicas relevantes para compreender a influência da música nas habilidades auditivas, linguísticas e cognitivas. Apesar da escassa produção científica sobre o tema, os estudos apresentados apontam relação positiva entre prática musical e desenvolvimento global infantil. $\mathrm{O}$ tema mais abordado foi o processamento auditivo, seguido do desenvolvimento cognitivo e da linguagem. A música pode ser considerada verdadeira aliada na terapia fonoaudiológica, demonstrando a importância da educação musical para crianças com desvio fonológico, alteração do processamento auditivo, distúrbio de linguagem oral e escrita. Baseado no que foi encontrado na revisão de literatura abrem-se novas perspectivas de trabalhos a serem realizados na fonoaudiologia para que as lacunas existentes possam ser preenchidas e que novos conhecimentos possam ser somados aos já construídos para a promoção do pleno desenvolvimento infantil.
\end{abstract}

DESCRITORES: Fonoaudiologia; Música; Linguagem; Percepção Auditiva; Cognição; Desenvolvimento Infantil

(1) Acadêmica do curso de Fonoaudiologia da Universidade Federal de Minas Gerais (UFMG), Belo Horizonte, Minas Gerais, Brasil.

(2) Fonoaudióloga; Doutoranda do Programa de Pós-graduação em Processos do Desenvolvimento Humano e Saúde (Universidade de Brasília); Mestre em Linguística Clínica pela University of Potsdam; Mestre em Música pela Universidade Federal de Minas Gerais - UFMG; Educadora Musical pela Universidade do Estado de Minas Gerais (UEMG);; Mestre em Linguística Clínica pela University of Potsdam.

(3) Fonoaudióloga; Professora Adjunto do Departamento de Fonoaudiologia da Universidade Federal de Minas Gerais - UFMG; Doutora em Ciências pela Universidade Federal de São Paulo - UNIFESP.

Conflito de interesses: inexistente

\section{INTRODUÇÃO}

A Fonoaudiologia é responsável pela promoção da saúde, prevenção, avaliação e diagnóstico, orientação, terapia (habilitação e reabilitação) e aperfeiçoamento dos aspectos relacionados à audição, função vestibular, linguagem oral e escrita, voz, fluência, articulação da fala e dos sistemas miofuncional, orofacial e cervical e de deglutição'.

O principal foco desta ciência é estudar e compreender os mecanismos da comunicação humana. Um dos pré-requisitos para haver comunicação oral é a audição², modalidade sensorial que permite ao homem perceber sons ${ }^{3}$. A audição 
propicia a captação sonora ambiental e permite ao indivíduo transformar as informações auditivas em mensagens significativas.

É importante considerar que sons são certas vibrações do meio que se transmitem ao órgão receptor da audição e são transformadas em potenciais bioelétricos para o processamento no sistema auditivo ${ }^{3}$. Então, por meio das situações dicóticas, oferecidas o tempo todo pelo ambiente, os indivíduos conseguem diferenciar as complexidades acústicas dos sons como intensidade, frequência e fase $^{4}$. Assim, para se processar a informação, via sentido da audição, os sons devem ser detectados e interpretados, ou seja, os estímulos acústicos são recebidos pelo sistema periférico e codificados neuralmente ${ }^{5}$.

A modalidade auditiva divide-se em algumas submodalidades: discriminação da intensidade sonora, discriminação tonal, identificação de timbres, localização espacial dos sons, compreensão da fala e a interpretação de sons complexos ${ }^{3}$, como, por exemplo, a música.

A música é a arte de combinar sons simultânea e sucessivamente, com ordem, equilíbrio e proporção dentro do tempo 6 . O estudo da percepção musical permite a análise minuciosa do som e influencia profundamente na formação do músico, pois atua como processo qualitativo do seu desenvolvimento em diversas subáreas: estudo de técnica, solfejo, ritmo, teoria, harmonia, etc ${ }^{6}$.

A compreensão adequada do som depende da integridade do sistema auditivo com um todo e o seu aprimoramento está relacionado, principalmente, a questões ambientais. Há pesquisa que indica que o ambiente musical no qual um ser humano cresce e se desenvolve possui papel fundamental no aguçamento do seu potencial de aprendizado dos elementos da música ${ }^{7}$. Logo, a percepção apurada dos elementos sonoros leva ao desenvolvimento adequado das habilidades auditivas, que facilitam o processo de aquisição e desenvolvimento da linguagem, bem como os mecanismos cognitivos.

Estudos constataram que o treinamento auditivo realizado para um tipo de estímulo sonoro pode ser generalizado para outros estímulos ou situações de escuta não utilizados nas situações de treinamento ${ }^{8}$. Sabe-se que a prática musical estimula o desenvolvimento da percepção auditiva melódica e harmônica por meio do treinamento perceptivo de intervalos, ritmo, entre outros parâmetros acústicos? ${ }^{9}$. Considerando a ocorrência de generalização, estas habilidades perceptivo-auditivas agem como facilitadores para a aquisição e para o desenvolvimento fonológico ${ }^{10}$, bem como para o aprimoramento das habilidades do processamento auditivo ${ }^{9}$.

Além disso, indivíduos com prática musical apresentam melhor desempenho em tarefas de matemática ${ }^{11}$, leitura ${ }^{12}$, vocabulário ${ }^{13}$, sintaxe $^{14} \mathrm{e}$ habilidades visuoespaciais ${ }^{15}$ e motoras $^{16}$. Estes achados demonstram significância estatística tanto em testes comportamentais ${ }^{10}$ quanto eletrofisiológicos ${ }^{17}$.

A fonoaudiologia se ocupa do desenvolvimento auditivo, bem como do desenvolvimento da linguagem, incluindo os aspectos metalinguísticos. Portanto, a música pode se tornar uma aliada no tratamento e prevenção de alguns distúrbios fonoaudiológicos.

Dada a relevância do tema, se faz primordial, inicialmente, a análise do conhecimento nacional e internacional já produzido, com o objetivo de oferecer subsídios para reflexões e ações na área da fonoaudiologia. Deste modo, o presente estudo tem por objetivo compilar os achados das áreas da fonoaudiologia e da música assim como buscar as relações entre a prática musical, desenvolvimento auditivo, cognitivo e linguístico.

\section{MÉTODO}

O presente estudo trata-se de revisão sistemática de literatura sobre trabalhos científicos que avaliaram a influência da educação musical no desempenho cognitivo, auditivo e linguístico de crianças e adolescentes. Esta revisão foi realizada no período de dezembro de 2010 a março de 2011 , incluindo como estratégia de pesquisa bases de dados eletrônicos - Scielo, Portal Capes, Pubmed, Medline e Google Acadêmico - e pesquisa manual de artigos referenciados.

Além das bases já citadas foram também incluídos artigos científicos, teses, dissertações, monografias, anais de participação em congressos e simpósios, do ano de 2001 a 2011, nos idiomas português, inglês e espanhol. Para a realização da busca, utilizaram-se os descritores: "música", "criança", "fonoaudiologia", "educação musical", "processamento auditivo", "músicos" e "não-músicos".

Sendo assim, os critérios de inclusão destas fontes de análise foram estudos que possuíam como amostra crianças e adolescentes, que, de acordo com a Organização Mundial da Saúde ${ }^{18}$ precisava ter até vinte anos de idade; estudos observacionais do tipo analítico (estudos transversais, caso-controle, coorte e retrospectivos) e estudos que tivessem, no máximo, dez anos de publicação.

O processo de seleção dos artigos ocorreu primeiramente por meio das buscas pelos descritores, artigos que atendessem à seguinte pergunta norteadora: "Qual a contribuição da música para o desenvolvimento das habilidades cognitivas, auditivas e linguísticas?". Em seguida foram 
selecionados os artigos nas línguas estipuladas e datas pré-determinadas nos critérios de inclusão. Por último, os estudos foram filtrados descartando os artigos com desfechos indesejados ou que possuíam pessoas adultas como foco de pesquisa.

$\mathrm{Na}$ etapa final do processo, os textos foram lidos, analisados e incluídos na discussão os que atenderam a todos os critérios de inclusão.

\section{REVISÃO DA LITERATURA}

Como já mencionado, o processo de análise dos artigos para estudo aconteceu por etapas, assim, na primeira seleção, foram encontrados trinta e um artigos utilizando-se os descritores mencionados. Na próxima fase, foram analisados os critérios de inclusão e exclusão preconizados e retirou-se da revisão sistemática dezoito artigos: quatorze pela amostra ser constituída por adultos, três por apresentarem desfechos indesejáveis ao objetivo do estudo e um artigo por ser uma revisão sistemática. Portanto, do total de artigos encontrados, treze atenderam aos critérios estipulados, sendo compatíveis com o objetivo do estudo. Dos artigos selecionados, cinco foram desenvolvidos no Brasil ${ }^{19-24}$, três nos Estados Unidos da América ${ }^{13,23-26}$, três no Canadá ${ }^{10,11,27}$, um na Alemanha ${ }^{25}$ e um em Portugal ${ }^{12}$.

As características de cada estudo estão detaIhadas nas figuras 1 a 3 . Com relação ao delineamento, considerou-se a classificação estipulada no estudo. Caso o artigo não tenha especificado o tipo de estudo realizado, fez-se a classificação da pesquisa, tendo como referência literatura específica de metodologia científica ${ }^{28}$.

\begin{tabular}{|c|c|c|c|}
\hline \multicolumn{3}{|c|}{ Características do Estudo } & \multirow{2}{*}{$\begin{array}{l}\text { Resultados } \\
\text { Principais achados } \\
\end{array}$} \\
\hline Estudo & Objetivos & Métodos & \\
\hline $\begin{array}{l}\text { Forgeard, et.al } \\
\text { Massachusetts, } \\
\text { Estados Unidos } \\
2008\end{array}$ & $\begin{array}{l}\text { Investigar a associação } \\
\text { entre a metodologia de } \\
\text { alfabetização musical } \\
\text { (tradicional ou Suzuki) na } \\
\text { infância e a aquisição de } \\
\text { habilidades cognitivas e } \\
\text { motoras. }\end{array}$ & $\begin{array}{l}\text { Delineamento: descritivo- } \\
\text { comparativo } \\
\text { Amostra: } 59 \text { crianças com idade } \\
\text { média de } 9.96 \text { anos de idade } \\
\text { Habilidades Testadas: } \\
\text { Percepção musical, destreza } \\
\text { manual, habilidade espacial, } \\
\text { teste de raciocínio não-verbal, } \\
\text { vocabulário, consciência } \\
\text { fonológica à nível de fonemas e } \\
\text { habilidades matemáticas. }\end{array}$ & $\begin{array}{l}\text { Não houve resultados com } \\
\text { significância estatística, entretanto, os } \\
\text { autores ressaltam: } \\
\text { - Deve-se receber, no mínimo } 3 \text { anos } \\
\text { de estudo (não importa o método) } \\
\text { para que as diferenças no } \\
\text { desempenho linguístico apareçam; } \\
\text { - As habilidades próximas de } \\
\text { discriminação auditiva e habilidades } \\
\text { motoras são mais predominantes em } \\
\text { quem possui treino musical; } \\
\text { - As habilidades de vocabulário e } \\
\text { raciocínio não verbal também são } \\
\text { mais significativas em quem possui } \\
\text { treino instrumental; } \\
\text { - O treino de um instrumento musical } \\
\text { não está associado a habilidades } \\
\text { matemáticas, fonêmicas ou espaciais. }\end{array}$ \\
\hline $\begin{array}{l}\text { Schellenberg } \\
\text { Ontario, Canadá } \\
2004\end{array}$ & $\begin{array}{l}\text { Verificar qual atividade - } \\
\text { aula de canto, teclado ou } \\
\text { interpretação - favorece o } \\
\text { desenvolvimento } \\
\text { cognitivo, comparando os } \\
\text { resultados com um grupo } \\
\text { controle. }\end{array}$ & $\begin{array}{l}\text { Delineamento: experimental } \\
\text { Amostra: } 144 \text { crianças de } 6 \text { anos } \\
\text { de idade } \\
\text { Habilidades Testadas: QI, } \\
\text { compreensão verbal, } \\
\text { organização espacial, aritmética, } \\
\text { desenho de blocos, vocabulário, } \\
\text { compreensão, leitura de } \\
\text { decodificação, ortografia e } \\
\text { compreensão de leitura. }\end{array}$ & $\begin{array}{l}\text { Todos os grupos tiveram aumento do } \\
\text { QI de forma significativa. Os grupos } \\
\text { que realizaram aulas de música } \\
\text { tiveram resultados maiores e similares } \\
\text { entre eles (teclado e voz). O grupo de } \\
\text { interpretação e o grupo controle } \\
\text { apresentaram crescimento do QI } \\
\text { similar entre eles e inferior ao grupo } \\
\text { de música. }\end{array}$ \\
\hline $\begin{array}{l}\text { Moreno, et.al } \\
\text { Aveiro, Portugal } \\
2008\end{array}$ & $\begin{array}{l}\text { Verificar a influência do } \\
\text { treino musical nas } \\
\text { habilidades cognitivas em } \\
\text { crianças que realizaram } \\
\text { aulas de música e pintura. }\end{array}$ & $\begin{array}{l}\text { Delineamento: } \\
\text { experimental/longitudinal } \\
\text { Amostra: } 37 \text { crianças de } 8 \text { anos } \\
\text { de idade } \\
\text { Habilidades Testadas: QI, } \\
\text { compreensão, aritmética e } \\
\text { vocabulário, leitura, memória } \\
\text { para sons verbais e para dígitos. }\end{array}$ & $\begin{array}{l}\text { As aulas de música proporcionaram } \\
\text { melhora significativa nas habilidades } \\
\text { de leitura e discriminação do pitch, } \\
\text { bem como a habilidade de fala, o que } \\
\text { não foi encontrado no grupo que } \\
\text { realizou aula de pintura. } \\
6 \text { meses de treino musical, duas } \\
\text { vezes na semana, é suficiente para } \\
\text { influenciar o desenvolvimento } \\
\text { cognitivo. }\end{array}$ \\
\hline
\end{tabular}

QI - Quociente de Inteligência

Figura 1 - Características dos estudos que avaliaram a influência musical nos processos cognitvos 


\begin{tabular}{|c|c|c|c|}
\hline \multicolumn{3}{|c|}{ Características do Estudo } & \multirow{2}{*}{$\begin{array}{l}\text { Resultados } \\
\text { Principais achados }\end{array}$} \\
\hline Estudo & Objetivos & Métodos & \\
\hline $\begin{array}{l}\text { Kurrle e Toniolo } \\
\text { Santa Maria, Brasil } \\
2004\end{array}$ & $\begin{array}{l}\text { Verificar a influência da } \\
\text { musicoterapia como } \\
\text { recurso terapêutico no } \\
\text { desempenho das } \\
\text { habilidades auditivas em } \\
\text { crianças com dificuldades } \\
\text { do processamento auditivo } \\
\text { e queixas no aprendizado } \\
\text { escolar. }\end{array}$ & $\begin{array}{l}\text { Delineamento: } \\
\text { experimental } \\
\text { Amostra: } 6 \text { crianças de } 6 \text { a } \\
9 \text { anos de idade } \\
\text { Habilidades Testadas: PA } \\
\text { (IPRF e Teste Dicótico de } \\
\text { Dissílabos Alternados) }\end{array}$ & $\begin{array}{l}\text { Significância estatística- todos os } \\
\text { sujeitos. A musicoterapia teve } \\
\text { influência positiva nas habilidades do } \\
\text { processamento auditivo }\end{array}$ \\
\hline $\begin{array}{l}\text { Cioqueta e Costa } \\
\text { Santa Maria, Brasil } \\
2006\end{array}$ & $\begin{array}{l}\text { Comparar os resultados da } \\
\text { avaliação do } \\
\text { processamento auditivo de } \\
\text { dois grupos de escolares: } \\
\text { um com, e outro, sem } \\
\text { experiência musical }\end{array}$ & $\begin{array}{l}\text { Delineamento: descritivo- } \\
\text { comparativo } \\
\text { Amostra: } 30 \text { crianças de } 7 \\
\text { a } 14 \text { anos de idade } \\
\text { Habilidades Testadas: PA } \\
\text { (SSW, fala no ruído, PPS e } \\
\text { DPS) }\end{array}$ & $\begin{array}{l}\text { Significância estatística - PPS grupo } \\
\text { de escolares com experiência musical } \\
\text { apresentou resultados melhores }\end{array}$ \\
\hline $\begin{array}{l}\text { Amatucci e Lupion } \\
\text { São Paulo, Brasil } \\
2001\end{array}$ & $\begin{array}{l}\text { Estudar o processamento } \\
\text { auditivo central em } 20 \\
\text { crianças integrantes do } \\
\text { coral da Unicastelo com } \\
\text { um tempo mínimo de } \\
\text { participação de um ano e } \\
20 \text { crianças sem prática de } \\
\text { participação em coral. }\end{array}$ & $\begin{array}{l}\text { Delineamento: descritivo- } \\
\text { comparativo } \\
\text { Amostra: } 20 \text { crianças } \\
\text { coralistas e } 20 \text { crianças } \\
\text { sem prática musical, de } 7 \text { a } \\
14 \text { anos de idade. } \\
\text { Habilidades testadas: } \\
\text { localização sonora, testes } \\
\text { de sequencialização } \\
\text { sonora com sons verbais e } \\
\text { com sons não-verbais e o } \\
\text { teste SSW. }\end{array}$ & $\begin{array}{l}\text { Crianças participantes e não- } \\
\text { participantes do coral apresentaram } \\
\text { desempenho dentro dos padrões } \\
\text { considerados normais. } \\
\text { Em relação ao teste SSW, os } \\
\text { aspectos quantitativos das crianças do } \\
\text { coral foi superior ao desempenho das } \\
\text { crianças não-participantes do coral. } \\
\text { Em relação aos aspectos qualitativos } \\
\text { do teste SSW, as crianças } \\
\text { participantes e não-participantes do } \\
\text { coral apresentaram desempenho } \\
\text { dentro dos padrões considerados } \\
\text { normais para as determinadas faixas } \\
\text { etárias. }\end{array}$ \\
\hline $\begin{array}{l}\text { Mendonça e Lemos } \\
\text { Belo Horizonte, Brasil } \\
2010\end{array}$ & $\begin{array}{l}\text { Comparar o desempenho } \\
\text { de crianças com e sem } \\
\text { musicalização em tarefas } \\
\text { de processamento auditivo } \\
\text { e apreciação musical. }\end{array}$ & $\begin{array}{l}\text { Delineamento: descritivo- } \\
\text { comparativo } \\
\text { Amostra: } 56 \text { crianças de } 5 \\
\text { anos de idade } \\
\text { Habilidades Testadas: PA } \\
\text { e Apreciação Musical }\end{array}$ & $\begin{array}{l}\text { Significância estatística - Prática } \\
\text { musical e habilidades auditivas; } \\
\text { prática musical e tarefa de apreciação } \\
\text { musical }\end{array}$ \\
\hline
\end{tabular}

PA - Processamento Auditivo, IPRF - Índice Percentual de Reconhecimento de Fala, SSW - Staggered Spondaic Words, PPS - Pitch Pattern Sequence, DPS - Duration Pattern Sequence.

Figura 2 - Características dos estudos que avaliaram a influência musical no processamento auditivo 


\begin{tabular}{|c|c|c|c|}
\hline \multicolumn{3}{|c|}{ Características do Estudo } & Resultados \\
\hline Estudo & Objetivos & Métodos & Principais achados \\
\hline $\begin{array}{l}\text { Groß, et.al } \\
\text { Witten, Alemanha } \\
2010\end{array}$ & $\begin{array}{l}\text { Verificar se sessões de } \\
\text { musicoterapia aplicadas } \\
\text { em crianças com atraso no } \\
\text { desenvolvimento da fala } \\
\text { auxilia no tratamento } \\
\text { fonoaudiológico }\end{array}$ & $\begin{array}{l}\text { Delineamento: estudo- } \\
\text { piloto observacional } \\
\text { Amostra: } 18 \text { crianças de } \\
3.5 \text { a .6 anos de idade } \\
\text { Habilidades Testadas: } \\
\text { Compreensão verbal, fala } \\
\text { produtiva, memória } \\
\text { operacional e teste de QI. }\end{array}$ & $\begin{array}{l}\text { A capacidade fonológica, de } \\
\text { compreensão e as habilidades } \\
\text { cognitivas, como atenção e memória, } \\
\text { melhorou significativamente após as } \\
\text { sessões de musicoterapia. }\end{array}$ \\
\hline $\begin{array}{l}\text { Anvari, et.al } \\
\text { Hamilton, Canadá } \\
2002\end{array}$ & $\begin{array}{l}\text { Verificar a relação entre } \\
\text { percepção musical e } \\
\text { aquisição precoce da } \\
\text { leitura em crianças sem } \\
\text { experiência musical }\end{array}$ & $\begin{array}{l}\text { Delineamento: } \\
\text { observacional descritivo } \\
\text { Amostra: } 50 \text { crianças de } \\
4 \text { e } 50 \text { crianças de } 5 \text { anos } \\
\text { de idade } \\
\text { Habilidades Testadas: } \\
\text { Consciência fonológica, } \\
\text { vocabulário receptivo, } \\
\text { percepção musical, } \\
\text { memória auditiva para } \\
\text { dígitos, aritmética e } \\
\text { leitura. }\end{array}$ & $\begin{array}{l}\text { Significância estatística - Correlação } \\
\text { entre habilidades fonológicas e } \\
\text { habilidade de leitura. } \\
\text { Nas duas idades, a habilidade } \\
\text { fonológica foi correlacionada com a } \\
\text { habilidade musical, sendo que aos } 4 \\
\text { anos já se observa a relação entre } \\
\text { habilidade musical e habilidade de } \\
\text { leitura e aos } 5 \text { anos, o processamento } \\
\text { do tom com o processamento de } \\
\text { leitura. } \\
\text { A habilidade musical se correlaciona } \\
\text { diretamente com o processamento } \\
\text { fonológico e capacidade de leitura nas } \\
\text { duas idades. A habilidade musical se } \\
\text { correlacionou ao processamento } \\
\text { auditivo apenas para as crianças de } 4 \\
\text { anos. } \\
\text { A relação entre habilidades } \\
\text { matemáticas, música e processamento } \\
\text { fonológico foi encontrada apenas nos } \\
\text { mais novos. }\end{array}$ \\
\hline $\begin{array}{l}\text { David, et.al } \\
\text { Ontario, Canadá } \\
2007\end{array}$ & $\begin{array}{l}\text { Determinar as relações } \\
\text { entre ritmo, leitura, } \\
\text { consciência fonológica e } \\
\text { nomeação rápida. }\end{array}$ & $\begin{array}{l}\text { Delineamento: } \\
\text { observacional descritivo } \\
\text { Amostra: } 38 \text { crianças da } \\
\text { First grade - Fifith grade } \\
\text { Habidades Testadas: } \\
\text { Consciência fonológica, } \\
\text { leitura, nomeação rápida } \\
\text { e percepção musical à } \\
\text { nível de ritmo }\end{array}$ & $\begin{array}{l}\text { Significância estatística - ritmo e } \\
\text { habilidade de leitura. } \\
\text { O ritmo está associado à leitura em } \\
\text { todas as séries, entretanto, a série mais } \\
\text { significativa foi a grade } 1 \text {. Quando a } \\
\text { variável da consciência fonológica é } \\
\text { eliminada, há uma evidência } \\
\text { significativa entre leitura e ritmo na } \\
\text { grade } 5 \text {. Quando retirada a variável de } \\
\text { nomeação rápida o ritmo não contribui } \\
\text { para a releitura na grade } 1 \text {, mas é } \\
\text { significativo na grade } 2,3 \text { e } 5 \text {. }\end{array}$ \\
\hline $\begin{array}{l}\text { Cardillo } \\
\text { Seattle, Estados Unidos } \\
2006\end{array}$ & $\begin{array}{l}\text { Investigar se a } \\
\text { compreensão da } \\
\text { informação prosódica está } \\
\text { relacionada com a } \\
\text { percepção do ritmo em } \\
\text { contextos musicais e } \\
\text { habilidades de consciência } \\
\text { fonológica }\end{array}$ & $\begin{array}{l}\text { Delineamento: } \\
\text { observacional descritivo } \\
\text { Amostra: } 23 \text { crianças de } \\
5 \text { anos de idade } \\
\\
\text { Habilidades Testadas: } \\
\text { prosódia, percepção } \\
\text { musical, consciência } \\
\text { fonológica e vocabulário. }\end{array}$ & $\begin{array}{l}\text { A prosódia está intimamente } \\
\text { relacionada às habilidades de } \\
\text { consciência fonológica e vocabulário. } \\
\text { Não houve significância entre prosódia } \\
\text { e percepção musical. O ritmo e o pitch } \\
\text { são processados de maneira diferente } \\
\text { pelas crianças nesta idade. O ritmo } \\
\text { está mais associado à consciência } \\
\text { fonológica e a prosódia do que o pitch. }\end{array}$ \\
\hline $\begin{array}{l}\text { Magne, et.al } \\
\text { Massachusetts, Estados } \\
\text { Unidos } \\
2006\end{array}$ & $\begin{array}{l}\text { Investigar se o treino } \\
\text { musical facilita o } \\
\text { processamento da } \\
\text { frequência, não apenas na } \\
\text { música, mas também na } \\
\text { língua. }\end{array}$ & $\begin{array}{l}\text { Delineamento: descritivo- } \\
\text { comparativo } \\
\text { Amostra: } 26 \text { crianças de } \\
8 \text { anos de idade } \\
\text { Habilidades Testadas: } \\
\text { Percepção das variações } \\
\text { tonais na música e na } \\
\text { fala. }\end{array}$ & $\begin{array}{l}\text { Significância estatística - Os praticantes } \\
\text { de música tiveram uma performance } \\
\text { significativa na percepção da variação } \\
\text { da frequência para agudo. Este } \\
\text { resultado foi encontrado tanto para os } \\
\text { testes com música como para os testes } \\
\text { com frases. Os resultados } \\
\text { eletrofisiológicos demonstraram maior } \\
\text { velocidade no processamento da } \\
\text { informação, no grupo de músicos. }\end{array}$ \\
\hline
\end{tabular}


$\mathrm{Na}$ figura 4 foram distribuídos os temas mais estudados nos últimos oito anos.

As habilidades cognitivas envolvidas na aprendizagem musical estão relacionadas à aquisição fonológica, desenvolvimento e abrangência da linguagem oral e escrita, desenvolvimento musical, aprimoramento do processamento auditivo e das habilidades matemáticas. Todas estas habilidades são focos de pesquisa fonoaudiológica, exceto o desenvolvimento musical, e podem ser importantes para auxiliar nas estratégias terapêuticas nos distúrbios de leitura e escrita, linguagem oral e processamento auditivo.

O foco de estudo mais comum entre os artigos selecionados foi o processamento auditivo ${ }^{19-22} \mathrm{e}$ a cognição ${ }^{11-14}$, sendo a abordagem comportamental ${ }^{10-27}$ mais frequente que a eletrofisiológica ${ }^{23}$. Por meio da pesquisa foi possível observar que a maior parte dos artigos encaixa-se no perfil longitudinal do tipo caso controle, o que demonstra que são estudos que permitem analisar o efeito da frequência e da exposição à música (aulas e estudo em casa). Salienta-se a importância de estudos longitudinais neste tema de pesquisa, pois as consequências do estudo da música são adquiridas à longo prazo ${ }^{11-13}$. Os estudos foram separados por eixos temáticos e serão apresentados a seguir.

Aproximadamente aos dois anos de idade a criança inicia seu repertório de palavras e é esperado que, até os sete anos de idade, ela cometa erros de omissão, sonorização, substituição ou inversão dos fonemas ${ }^{29}$. Há estudos que comprovam a integração cortical entre o processamento musical e linguístico ${ }^{30}$. Dos treze artigos incluídos, dois ${ }^{25,26}$ pesquisaram a relação música e desenvolvimento fonológico. Por estas análises, foi possível identificar

\begin{tabular}{|l|l|l|l|}
\hline \multicolumn{3}{|c|}{ Características do Estudo } & Resultados \\
\hline Estudo & Objetivos & Métodos & Principais achados \\
\hline Mendonça & $\begin{array}{l}\text { Investigar relações entre } \\
\text { desenvolvimento musical e } \\
\text { desenvolvimento das } \\
\text { habilidades auditivas e } \\
\text { fonológicas em crianças } \\
\text { com tempo de prática } \\
\text { musical diferente }\end{array}$ & $\begin{array}{l}\text { Delineamento: descritivo- } \\
\text { comparativo }\end{array}$ & $\begin{array}{l}\text { Habilidades auditivas mais } \\
\text { desenvolvidas em crianças com maior } \\
\text { tempo de estudo de música. Provável } \\
\text { relação entre estudo de música e } \\
\text { aquisição fonética }\end{array}$ \\
& $\begin{array}{l}\text { e 6 anos de idade } \\
\text { Habilidades Testadas: PA, } \\
\text { fonologia, composição e } \\
\text { performance musical }\end{array}$ & \\
\hline
\end{tabular}

PA - Processamento Auditivo

Figura 4 - Características dos estudos que correlacionaram música, processamento auditivo, linguagem e cognição

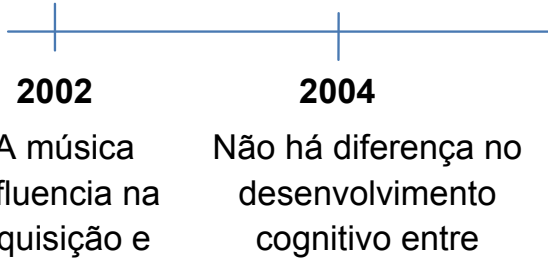

desenvolvimento crianças que praticam fonológico e se canto ou instrumento. relaciona com habilidades de leitura.
Toda atividade musical exerce influência sobre o desenvolvimento cognitivo.

\begin{tabular}{|c|c|c|}
\hline 2006 & 2008 & 2010 \\
\hline $\begin{array}{c}\text { Crianças que } \\
\text { estudam música } \\
\text { percebem melhor a } \\
\text { diferença de variação } \\
\text { da frequência, tanto } \\
\text { na música quanto na } \\
\text { fala do que crianças } \\
\text { que não estudam } \\
\text { música. }\end{array}$ & $\begin{array}{l}\text { O tempo de estudo } \\
\text { musical é fator } \\
\text { importante para } \\
\text { determinar as } \\
\text { consequências no } \\
\text { desenvolvimento } \\
\text { auditivo, linguístico } € \\
\text { cognitivo. }\end{array}$ & $\begin{array}{c}\text { Atenção e } \\
\text { memórias são as } \\
\text { principais } \\
\text { habilidades } \\
\text { cognitivas que } \\
\text { melhoram após } \\
\text { exposição à } \\
\text { música. Estas } \\
\text { habilidades estão } \\
\text { relacionadas com o } \\
\text { desenvolvimento de } \\
\text { linguagem e } \\
\text { aprimoramento do } \\
\text { processamento } \\
\text { auditivo. }\end{array}$ \\
\hline
\end{tabular}

Figura 5 - Cronologia dos estudos de acordo com os assuntos mais abordados em cada ano 
que pesquisa brasileira ${ }^{25}$ recrutou crianças de três e seis anos de idade e com diferentes tempos de prática musical e, por meio da Avaliação Fonológica da Criança, verificou que crianças mais novas e com maior tempo de prática musical não possuíam processos fonológicos, enquanto que as mais velhas ainda estavam em fase de aquisição fonêmica. Estudo alemão ${ }^{26}$ verificou a influência da musicoterapia no tratamento de crianças com desvio fonológico de três anos e cinco meses a seis anos de idade. As sessões de musicoterapia ocorreram por oito semanas consecutivas. Os participantes foram avaliados, antes e após a estimulação musicoterápica, em testes de memória para sons verbais, compreensão da fala e nomeação de figuras para criar o inventário fonológico de cada criança. Os resultados mostraram que, após as oito sessões de musicoterapia, as crianças continuaram com seus desvios fonológicos, entretanto, apresentaram melhoras com significância estatística para a memória e compreensão da fala, habilidades importantes para o sucesso na terapia de fala.

É importante lembrar que processamento auditivo é a série de etapas que se sucedem no tempo e permitem o indivíduo realizar análises acústicas e metacognitivas do som ${ }^{31}$. Diante disto, a integridade das habilidades do processamento auditivo permite que o indivíduo se comunique adequadamente e se organize no espaço em que ocupa. Além do mais, o desenvolvimento adequado do processamento auditivo é a base da aprendizagem de qualquer tipo e nível ${ }^{32}$. Na literatura geral, há relativa riqueza de estudos com foco de investigação nas habilidades de ordenação e resolução temporal ${ }^{33,34}$, na discriminação da frequência em sons verbais e não verbais $^{35}$ e memória auditiva para sons verbais e não verbais ${ }^{36}$. Dentre os estudos incluídos, quatro deles citaram a relação da música e do processamento auditivo e dois correlacionaram música, habilidades linguísticas e auditivas.

Estudo nacional ${ }^{23}$ avaliou escolares com e sem experiência musical nos testes Staggered Spondaic Words (SSW), fala no ruído, Pitch Pattern Sequence (PPS) e Duration Pattern Sequence (DPS). Em relação aos testes SSW e fala no ruído, o grupo de escolares com experiência musical, alfabetizados pelo método Suzuki, apresentou valores superiores, porém, não estatisticamente significantes, quando analisadas as orelhas avaliadas. Considerando o teste DPS, o mesmo ocorreu. Já para o teste PPS, que consiste na apresentação de três sequências tonais que se diferenciam em frequência, o grupo de escolares com experiência musical apresentou resultados melhores, estatisticamente significantes, tanto para a análise das orelhas avaliadas, quanto para a forma de resposta dos escolares. Ainda como resultado observou-se em todos os testes aplicados, que as respostas do grupo de escolares com experiência musical foram melhores e mais claras, de modo que os resultados qualitativos diferiram significantemente dos resultados do grupo de escolares sem experiência musical. Outro estudo nacional ${ }^{22}$, comparou o desempenho de crianças de cinco anos com e sem musicalização em tarefas de processamento auditivo e apreciação musical. Os resultados demonstram que a prática musical exerce influência positiva sobre habilidades auditivas avaliadas nos testes de memória sequencial verbal e não-verbal com quatro estímulos sonoros e na tarefa de apreciação musical, com significância estatística. Em outro estudo brasileiro ${ }^{20}$ que avaliou o desempenho de vinte crianças integrantes de um coral em habilidades de sequencialização sonora para sons verbais e não verbais, localização sonora e realização do teste SSW não foi encontrada significância estatística entre grupo caso e grupo controle para as habilidades de localização sonora, sequencialização sonora tanto para sons verbais, quanto não verbais. Entretanto, o desempenho quantitativo no teste SSW apresentou significância estatística para os participantes do coral.

Assim como no estudo alemão ${ }^{27}$, que avaliou a influência da musicoterapia para o desenvolvimento

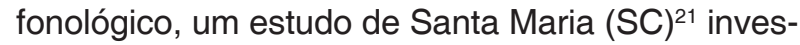
tigou se a musicoterapia oferece benefício terapêutico aos portadores das desordens do processamento auditivo. Para isso, recrutaram-se vinte e duas crianças que apresentavam queixas de dificuldades auditivas, mas que apresentavam exames auditivos normais. Das vinte e duas crianças, dezesseis foram diagnosticadas como portadoras das desordens do processamento auditivo. As crianças foram submetidas à avaliação do Índice Percentual do Reconhecimento de Fala (IPRF) e o teste SSW. Os indivíduos foram classificados em normal, leve, moderado ou severo, de acordo com a normatização para a classificação das desordens do processamento auditivo ${ }^{37}$. Somente seis responsáveis concordaram em realizar as sessões musicoterápicas e após doze estimulações, as crianças foram analisadas novamente no teste SSW. Dos seis sujeitos avaliados, três passaram do grau severo para o moderado, dois passaram do moderado para leve e um permaneceu com o grau moderado, porém melhorou o desempenho qualitativo no teste proposto.

A consciência fonológica faz parte do desenvolvimento e da abrangência da linguagem oral e escrita $^{38}$. Esta habilidade se desenvolve ao longo da vida e se relaciona diretamente com o nível escolar, profissão, hábitos de leitura, escrita e das exigências do meio em que vive o indivíduo ${ }^{39}$. Tanto a 
música quanto a língua respeitam regras sonoras e gramaticais hierárquicas ${ }^{40}$, assim a música pode facilitar a compreensão da língua e vice-versa. Sendo assim, três artigos citaram a relação entre linguagem oral e escrita e música.

Contudo, estudo canadense ${ }^{10}$ analisou e comparou a percepção musical, a consciência fonológica, o vocabulário, as habilidades matemáticas e a habilidade de leitura em pré-escolares sem prática musical na região de Hamilton-Wentworth. Participaram deste estudo 50 crianças na faixa etária de quatro anos e 50 crianças de cinco anos de idade. Com relação à consciência fonológica, avaliou-se a rima, exclusão, adição, segmentação e comparação fonêmica em diferentes posições na palavra e reorganização fonêmica para formar uma nova palavra. Em ambos os grupos foi encontrada uma relação, com significância estatística, entre consciência fonológica e aquisição de leitura. Houve significância estatística também entre as habilidades de processamento musical, processamento fonológico e processamento de leitura, sendo estas três habilidades intimamente relacionadas. Em contrapartida, outro estudo americano ${ }^{26}$ comparou o desempenho de vinte e três crianças de cinco anos de idade em habilidades rítmicas, a prosódia e a consciência fonológica. Assim como no estudo supracitado $^{10}$, a amostra deste estudo não foi composta por estudantes de música. Encontrou-se que a prosódia e o ritmo estão relacionados à consciência fonológica, mas não houve significância estatística para prosódia e percepção musical. Nos estudos citados, as crianças não possuíam prática musical, assim os resultados encontrados poderiam ser mais robustos, caso utilizados estudos do tipo caso controle.

As escalas musicais são constituídas por sons que têm relações matemáticas precisas entre si e, quando combinadas de determinadas maneiras, podem produzir resultados agradáveis aos ouvidos ${ }^{41}$. Essas relações matemáticas, junto com as características intrínsecas das vibrações sonoras, são a base para a harmonia na superposição dos sons musicais. Além do mais, a maneira como se encadeia os sons na música também segue regras com fundamentos matemáticos. Todos os tipos de ritmos que se pode conceber musicalmente obedecem a algum tipo de divisão fracionária, cuja característica sempre está vinculada a um determinado gênero artístico ou a um tipo de cultura. Assim, o aprendizado musical formal fornece desafios matemáticos a todo o momento, uma vez que a base da teoria musical e acústica do som segue cálculos matemáticos complexos e de difícil compreensão. O sistema de pensamento superior $^{42}$ é responsável pelo raciocínio lógico, pela resolução de problemas, pela formação e utilização de conceitos, pela compreensão de como e onde as regras são aplicadas e válidas e pelas idéias complexas. Dos três estudos que citaram a relação música e cognição ${ }^{11-13}$, todos foram compostos de testes aritméticos.

Com relação aos processos cognitivos, estudo canadense ${ }^{11}$ avaliou o Quociente de Inteligência (QI) em 144 crianças de seis anos distribuídas em quatro grupos. O primeiro grupo fez aulas de canto, já o segundo, aulas de teclado, o terceiro, aulas de teatro e, no entanto, o último não realizou atividades culturais. As aulas foram ministradas em um ano por professores colaboradores que utilizaram a mesma técnica de ensino para todas as crianças. A habilidade aritmética, além de outras habilidades, fez parte dos subtestes de avaliação. Foram encontrados resultados com significância estatística nos grupos que realizaram aulas de música, sobretudo no grupo que realizou aula de canto. Entretanto, não houve diferença estatisticamente significante entre os grupos que fizeram aulas de teclado e aulas de canto. Um ponto importante que o autor destaca, é o fato das crianças avaliadas terem se desenvolvido intelectualmente na escola regular, o que contribuiu para o aumento do QI em todos os grupos.

Estudo canadense ${ }^{10}$, também avaliou a capacidade de resolver problemas matemáticos simples. Os testes utilizados consistiram em dois problemas de adição e dois problemas de subtração numérica. Por meio da análise de regressão, o autor comparou os resultados dos problemas matemáticos com a habilidade de leitura e habilidade musical, que envolveu melodia e ritmo. Os resultados mostraram que a relação destas habilidades foram estatisticamente significantes somente nas crianças com quatro anos, o que sugere que a habilidade matemática não está envolvida na relação música e leitura. Salienta-se que neste estudo ${ }^{10}$, os sujeitos de pesquisa não praticavam aulas de música.

Todas as habilidades anteriormente citadas, além de outras como o processamento visual, são pré-requisitos para o desenvolvimento adequado de leitura e escrita ${ }^{43}$, uma vez que o indivíduo que inicia o processo de alfabetização necessita possuir desenvolvimento adequado do processamento auditivo ${ }^{44}$, da fonologia ${ }^{45}$ e da consciência fonológica ${ }^{46}$. Apenas um estudo buscou a habilidade de leitura com habilidades musicais, como o ritmo. Assim como nos estudos canadenses ${ }^{10,27}$ não selecionaram grupos casos e controles, ou seja, nenhum dos indivíduos possuía experiência musical comprovada. $\mathrm{O}$ autor realizou testes de consciência fonológica em nível de sílaba e fonema, testes de nomeação rápida, testes de leitura para palavra e 
pseudopalavra e testes musicais que envolviam o ritmo. Os sujeitos da pesquisa eram crianças que estavam do primeiro ao quarto ano de escolarização, segundo a classificação norte-americana. $O$ autor verificou que o ritmo está associado à leitura em todas as séries avaliadas, porém, a única com significância estatística foi a first grade (primeira série). Quando a variável da consciência fonológica foi eliminada, houve significância estatística entre leitura e ritmo na fifith grade (quinta série). Com a retirada da variável de nomeação rápida o ritmo não contribuiu para a releitura na first grade (primeira série), mas foi evidente nas second, third e fifith grade (segunda, terceira e quinta série), mostrando diferença estatística entre ritmo e habilidade de leitura.

Estudos que investigam a relação do desenvolvimento cognitivo com a prática musical devem ser delineados com cuidado, considerando que as possibilidades de erro são grandes. Um critério de inclusão importante a ser levado em conta e que somente três ${ }^{11,13,23}$ estudos utilizaram como variável de análise foi o tempo de estudo de música dos participantes do estudo.

Observa-se então que, estudo português ${ }^{12}$, cita que são necessários, no mínimo, seis meses de estudo de música formal para que haja modificação da plasticidade cerebral, demonstrada com testes eletrofisiológicos. Por conta deste achado, um estudo americano ${ }^{13}$ incluiu somente sujeitos com, no mínimo, três anos de estudo. O terceiro trabalho ${ }^{11}$ incluiu crianças com, pelo menos, um ano de estudo musical formal pelo método Kodály, o que tornou seus resultados mais sólidos e confiáveis. Além do mais, é importante saber as horas de estudo semanais da criança, o instrumento praticado e se ela possui o hábito de estudar em casa. Estes dados fornecem informações importantes, pois dizem respeito à dedicação da criança ao instrumento praticado e qual o grau de dificuldade ou motivação da criança em relação à prática musical. Estudo de Massachusetts ${ }^{13}$ que levou em consideração as horas de prática musical em casa, evidenciou que quanto maior o tempo de estudo durante a semana, maior o desempenho em tarefas cognitivas e motoras. Diferentemente da maioria dos estudos analisados, estudo americano ${ }^{23}$, além de especificar que as crianças deveriam ter entre um e quatro anos de estudo, especificou também que casos e controles deveriam ter perfil socioeconômico similares, definiu os instrumentos que o grupo caso deveria tocar, incluiu somente crianças que tinham treino diário de pelo menos vinte minutos, e ainda especificou que o grupo controle deveria realizar alguma atividade extra, diferente da prática musical. Então, criar critérios de inclusão e exclusão muito detalhados, podem reduzir a amostra do estudo, entretanto, oferecem menor probabilidade de erros. Assim, é importante investigar estes hábitos por meio de instrumentos direcionados aos pais e aos participantes, o que não foi muito frequente nos estudos analisados.

Durante a pesquisa realizada foram encontrados estudos que relatam relação estatisticamente significante entre música e o aprimoramento do processamento auditivo ${ }^{19-22}$, desenvolvimento linguístico ${ }^{10,23-27}$, a aquisição e desenvolvimento fonológico ${ }^{25,26}$ e do aprimoramento cognitivo ${ }^{11-13}$.

A pesquisa sobre o tema vem sendo realizada tanto sob o paradigma comportamental como eletrofisiológico. Essa revisão levantou prioritariamente os estudos comportamentais, mas é importante que estudos futuros procurem associar ambas as abordagens para ampliar a compreensão das relações entre experiência musical e desenvolvimento infantil.

Muitos dos estudos revisados trazem delineamentos de pesquisa tranversais (experimentais ou quasi-experimentais), ressalta-se a importância de estudos longitudinais sobre o tema, já que esse tipo de delineamento possibilita a observação do desenvolvimento infantil ao longo do tempo.

Ressalta-se ainda a importância dos critérios de inclusão e exclusão da amostra e dos instrumentos de coleta utilizados na pesquisa, uma vez que os viés encontrados neste tipo de estudo são extremamente elevados.

Além disso, é importante também investigar percepções e posições de pais, educadores e fonoaudiólogos sobre o papel da música no desenvolvimento infantil, já que estes atores estão diretamente envolvidos nesses processos.

Deste modo, ressalta-se a importância da pesquisa científica sobre este tema, principalmente na área da fonoaudiologia. Este artigo fornece um compilado dos estudos mais importantes realizados no Brasil, o que pode nortear muitos pesquisadores brasileiros, já que as publicações sobre o tema são escassas. A pesquisa multidisciplinar ainda é um desafio, que deve ser superado na busca da construção da unidade de conhecimentos, em especial quando trata-se do desenvolvimento infantil.

Com relação às limitações deste estudo, citam-se os critérios de exclusão estabelecidos neste estudo para que ele pudesse responder à pergunta norteadora. O tema abordado é extremamente abrangente e não poderia ser esgotado nesse artigo. Assim, é necessário que outras revisões sejam realizadas, abordando estudos em outras línguas, com faixa etária distinta da buscada e que aborde a eletrofisiologia cerebral, para a completa compreensão das consequências da musica. 


\section{CONCLUSÃO}

Apesar do número reduzido de artigos encontrados que buscassem relacionar música e desenvolvimento auditivo, cognitivo e linguístico, todos os trabalhos revisados e aqui apresentados demonstraram relações positivas entre prática musical e desenvolvimento global infantil. Salienta-se a importância da investigação científica sobre o tema, uma vez que alguns dos resultados encontrados foram divergentes quanto às inter-relações entre música e habilidades comunicativas, metalinguísticas e auditivas, mesmo que todos apontem para uma afinidade positiva entre as áreas.Para o indivíduo se comunicar de forma efetiva, deve haver internalização das habilidades básicas para a comunicação humana. A fonoaudiologia pode auxiliar no aperfeiçoamento das habilidades auditivas, linguísticas e cognitivas. Os resultados da terapia fonoaudiológica podem ser conquistados de maneira prazerosa e eficaz, caso a música seja aliada da intervenção terapêutica.

Baseado no que foi encontrado na literatura abrem-se novas perspectivas de trabalhos a serem realizados na fonoaudiologia para que as lacunas existentes possam ser preenchidas e que novos conhecimentos possam ser somados aos já construídos e consolidados para a promoção do pleno desenvolvimento infantil.

\section{ABSTRACT}

Music is an important environmental factor for developing motor, hearing, language, cognitive and visual skills, among others. Recent studies refer to the relationship between music study and improving the auditory processing, linguistic and metalinguistic abilities and cognitive processes that are inherent skills in human communication. Speech-Language and Hearing Therapy is concerned with the acquisition, development and refinement of skills necessary for human communication. Thus, there seems to be an interrelationship between the areas of Music and Speech-Language and Hearing Therapy. The purpose of this study is to describe and analyze the scientific production relevant to understanding the influence of music in the auditory, linguistic and cognition activities. Despite scarce scientific literature on the theme, the studies suggest a positive relation between musical practice and children's overall development. Auditory processing has been the theme that is more often addressed in the literature, followed by cognition development and language. Music can become a real ally in Speech-Language and Hearing Therapy, demonstrating the importance of music education for children with speech and auditory processing disorders, as well as oral and written language disturbs. Based on what was found in the literature review, new prospects of work to be conducted in SpeechLanguage and Hearing Therapy are opened, so that the shortcomings may be overcome and new knowledge can be summed to the already built up in order to promote full development of the children.

KEYWORDS: Speech, Language and Hearing Sciences; Music; Language; Auditory Perception; Cognition; Child Development

\section{REFERÊNCIAS}

1. Fonosp.org.br. [homepage da internet]. Conselho Regional de Fonoaudiologia. São Paulo. Inc.; c2000-01[Atualizada em Maio de 2011; acesso em 7 de julho de 2011]. Disponível em: http://www. fonosp.org.br/

2. Tanaka MRT, Araújo VM, Assencio-Ferreira VJ. Déficits de audição em idosos dificultariam a comunicação? Rev CEFAC. 2003:4(1);203-5.

3. Lent R. Os sons do mundo: estrutura e funções do sistema auditivo. In: Lent, R. Cem bilhões de neurônios: conceitos fundamentais de neurociências. 2a ed. Rio de Janeiro; Atheneu; 2005; p. 241-70.

4. Schweitzer C. Condições binaurais e direcionais para a reabilitação auditiva. In: Almeida, K; Iorio, MCM. Próteses auditivas: fundamentos teóricos e aplicações clínicas. $2^{\underline{a}}$ ed. São Paulo: Lovise, 2003; p.95-118.

5. Ríos AA, Rezende AG, Pela SM, Ortiz KZ, Pereira LD. Teste de padrão harmônico em escuta dicótica com dígitos - TDDH. Rev Soc Bras Fonoaudiol. 2007;12(4):304-9.

6. Rodrigues FM. Sistema online de música e percepção, uma proposta de auxílio à educação 
musical à distância: aprendizagem significativa e a percepção musical. [Monografia]. Brasília; Universidade de Brasília, Instituto de Ciências Exatas, Departamento de Ciências da Computação; 2008.

7. Jesus EA. Zorelha: Um objeto de aprendizagem para auxiliar no desenvolvimento da percepção musical em crianças de 4 a 6 anos [Trabalho de Conclusão de Curso]. Itajaí (SC). Universidade do Vale do Itajaí; Centro de Ciências Tecnológicas da Terra e do Mar, Curso de Ciências da Computação; 2008.

8. Oxenham AJ, Fligor BJ, Mason CR, Kidd G. Informational masking and musical training. J. Acoust Soc. 2003;114(3):143-9.

9. Soncini $F$, Costa MJ. Efeito da prática musical no reconhecimento da fala no silêncio e no ruído. Pró-Fono Rev Atual Cient. 2006; 18(2):161-70.

10. Anvari SH, Trainor LJ, Woodside J, Levy BA. Relations among musical skills, phonological processing, and early reading ability in preschool children. J Exp Child Psyc. 2002;83(2):111-30.

11. Schellenberg EG. Music lessons enhance IQ. American Psyc Society Res. 2004;15(8):511-4.

12. Moreno S, Marques C, Santos A, Santos M, Castro SL, Besson M. Musical training influences linguistic abilities in 8-year-old children: more evidence for brain plasticity. Cerebral Cortex March Res. 2008;19(3):712-23.

13. Forgeard M, Winner E, Norton A, Schlaug G. Practicing a musical instrument in childhood is associated with enhanced verbal ability and nonverbal reasoning. Plosone Res. 2008;10(3):1-8.

14. Slevc LR, Rosenberg JC, Patel AD. Making psycholinguistics musical: Self-paced reading time evidence for shared processing of linguistic and musical syntax. Psyc Bull \& Rev.2009:16 (2);374-81. 15. Sluming V, Brooks J, Howard M, Downes JJ,Roberts N. Broca's area supports enhanced visuospatial cognition in orchestral musicians. J. Neuroscience. 2007:27(14):3799-806.

16. Zatorre RJ, Chen JL, Penhune VB. When the brain plays music: auditory-motor interactions in music perception and production. Nature Neuros Res. 2007:8(10):547-58.

17. Gordon RL, Schön D, Magne C, Astésano C, Besson M. Words and melody are intertwined in perception of sung words: eeg and behavioral evidence. Plosone Res. 2010: 5(3):1-12.

18. Who.int [homepage da internet]. World Health Organization. Inc.;c2000-01[Atualizada em 20 de Junho de 2011; acesso em 9 de Julho de 2011]. Disponínel em: http://www.who.int/en/

19. Amatucci MAFC, Lupion AS. Das habilidades auditivas de localização, memória e figura-fundo em crianças integrantes do coral da unicastelo. Fono Atual Res. 2001; 5(18):13-7.

20. Kurrle MM, Toniolo IMF. Musicoterapia nas dificuldades do processamento auditivo. [Dissertação de Mestrado]. Santa Maria (RS): Universidade Federal de Santa Maria. Programa de Pós-Graduação em Distúrbios da Comunicação Humana. Departamento de Fonoaudiologia; 2004.

21. Mendonça JE, Lemos SMA. Relações entre prática musical, processamento auditivo e apreciação musical em crianças de cinco anos. Rev ABEM. 2010;23(1):58-66.

22. cioqueta ep, costa mj. efeito da prática musical no processamento auditivo em escolares de sete a 14 anos de idade. [Dissertação de mestrado]. Santa Maria (RS): Universidade Federal de Santa Maria. Curso de Pós-Graduação em Distúrbios da Comunicação Humana. Centro de Ciências da Saúde; 2006.

23. Magne C, Schön DM, Besson M. Musicians children detect pitch violations in both music and language better than nonmusician children: behavioral and electricophysiologycal approaches. J Cogn Neuros Res. 2006;18(2):199-211.

24. Mendonça JE. Educação musical e suas relações com habilidades auditivas e o desenvolvimento fonológico de crianças de três e seis anos. IV Simpósio de Cognição e Artes Musicais: São Paulo, ANAIS DO SIMCAM, 2008.

25. Groß W, Linden U, Ostermann T. Effects of music therapy in the treatment of children with deleyed speech development: results of a pilot study. BMC Complem Alternative Med. 2010;39(10):3-10.

26. Cardillo GC. Relationships among prosodic sensitivity, musical processing, and phonological awareness in pre-readers. Speech Prosody: Campinas, ISCA Archive, 2008.

27. David D, Wade-Woolley L, Kirby JR, Smithrim $\mathrm{K}$. Rhythm and reading development in school-age children: a longitudinal study. J Research in Reading. 2007; 30(2): 169-83.

28. Vieira S, Hossne WS. Metodologia científica para a área da saúde. $12^{\underline{a}}$ ed. Rio de Janeiro: Elsevier, 2003.

29. Wertzner HF. Fonologia (Parte A). In: Andrade CRF, Befi-Lopes DM, Fernandes FDM, Wertzner HF. ABFW - Teste de linguagem infantil. São Paulo: Pró-Fono. 2000;p.5-40.

30. Fedorenko E, Patel A, Winawer J, Casasanto D, Gibson E. Structural integration in language and music: evidence for a shared system. Memory Cognition Res. 2009;37(1):1-9.

31. Pereira LD. avaliação do processamento auditivo central. In: Filho, OL. Tratado de Fonoaudiologia. $2^{\mathrm{a}}$ ed. Ribeirão Preto: Tecmedd, 2005; p.109-26. 
32. Pinheiro FH, Capellini SA. Desenvolvimento das habilidades auditivas de escolares com distúrio de aprendizagem, antes e após treinamento auditivo, e suas implicações educacionais. Rev Psicopedagogia. 2009;26(80):231-41.

33. Neves VT, Freitosa, MGG. Controvérsias ou complexidade na relação entre processamento temporal auditivo e envelhecimento. Rev Bras Otorrinolaringol. 2003;69(2):242-9.

34. Ishii C, Arashiro PM, Pereira LD. Ordenação e resolução temporal em cantores profissionais e amadores afinados e desafinados. Pró-Fono Rev Atual Cient. 2006;18(3):285-92.

35. Monteiro RAM, Nascimento FM, Soares CD, Ferreira, MIDC. Habilidades de resolução temporal em músicos violinistas e não músicos. Arq Int Otorrinolaringol. 2010;14(3):302-8.

36. Tervaniemi M, Just V, Koelsch $S$, Widmann A, Schröger E. Pitch discrimination accuracy in musicians vs nonmusicians: an event-related potencial and behavioral evidence. Exp Brain Res. 2005;16(1):1-10.

37. Pallesen KJ, Brattico E, Bailey CJ, Korvenoja A, Koivisto J, Gjedd, A, et.al. Cognitive control in auditory working memory is enhanced in musicians. Plosone Res. 2010;5(6):1-12.

38. Capovilla AGS, Dias NM, Montiel JM. Desenvolvimento dos componentes da consciência fonológica no ensino fundamental e correlação com nota escolar. Psico-USF. 2007;12(1):55-64.
39. Pereira LD. processamento auditivo central abordagem passo a passo. In: Pereira LD, Schochat E. Processamento Auditivo Central: Manual de Avaliação. São Paulo: Lovise. 1997;p.49-60.

40. Hannon EE, Trainor LJ. Music acquisition: effects of enculturation and formal training on development. Trends Cognitive Sciences. 2007:11(11):466-72.

41. Alvarenga LG. O fenômeno sonoro: análise física. In: Alvarenga, LG. Breve Tratado Sobre o Som e a Música. Goiás: Cerne, 1992;p.13-28.

42. Ilari, B. A Música e o cérebro: algumas implicações do neurodesenvolvimento para a educação musical. Rev da ABEM. 2003;9(9):7-16.

43. Capovilla AGS, Gütschow CRD, Capovilla FC. habilidades cognitivas que predizem competência de leitura e escrita. Psicol Teoria e Prática. 2004;6(2):13-26.

44. Kozlowski L, Wiemes GMR, Magni C, Silva ALG. A efetividade do treinamento auditivo na desordem do processamento auditivo central. Rev Bras Otorrinolaringol. 2004;70(3):427-32.

45. Salgado C, Capellini SA. Desempenho em leitura e escrita em escolares com transtornos fonológicos. Res Pisicol Escolar e Educacional. 2004;8(2):179-88.

46. Pestun MSV. consciência fonológica no início da escolarização e o desempenho ulterior em leitura e escrita: estudo correlacional. Estudos de Psicologia. 2005;10(3):407-12.
http://dx.doi.org/10.1590/S1516-18462012005000038

RECEBIDO EM: 21/07/2011

ACEITO EM: 27/10/2011

Endereço para correspondência:

Stela Maris Aguiar Lemos

Av. Alfredo Balena, no 190, Sala 251,

Bairro Santa Efigênia

Belo Horizonte - MG

CEP: 30130-100

E-mail: lemos.stela@gmail.com 